\title{
Editorial
}

\section{For many companies 'Customer Driven Marketing' is no longer a vision, but also a headache. Why?}

Do we feel customer information is empowering us to do a better job of marketing financial services than was being done 10-15 years ago? In particular, is today's use of Customer Information living up to its promise of marketing advantage, despite the major investments made? The quest for 'relevant' 'customer driven marketing' is challenged by several barriers that remain relatively unaddressed.

Revolutions in technology and data availability have challenged previously well-established business models for the marketing and delivery of financial services, bringing many new offerings to consumers, especially via direct channels. And given this sector's product variety, lifetime values, margins and frequency of transactions, the 'customer relationship marketing (CRM) movement' has been hard at work. As a result, competition has rapidly intensified: a recipe for innovation and change. Yet, I repeat the question: are we doing a better job than before?

I recently responded to an online survey from a company asking me several questions about my perceptions of our 'relationship'. Unoriginally, I commented that I do not 'have a relationship, I only have an account'. With my relatively inactive deposit account I have never interacted with this company, yet have received a continuous regular stream of mailings and e-mails over several years. I joined because of a good interest rate at the time, and have remained, given the marginal benefits I perceive I would obtain in switching. I wonder how my information is being read. Am I successfully retained? Inactive? Profitable? High potential? High risk? Segment X?

Communications via telephone, mail and internet with many suppliers in this sector, repeatedly underline their clear difficulty in trying to be genuinely 'relevant' or easy to deal with, despite the technological and information advances available. This puts the many customerfocused mantras, plans and claims made, in a stark light: have these investments actually delivered market advantage and incremental profit? And quite apart from shareholders, do consumers perceive they are receiving more value than before?

As a consumer, and convert to online banking, I still feel I am more a victim than an advocate of any of my financial services suppliers whenever I need to contact them offline. There are a small number, however, who feel quite differently about their 'relationships': for example, what are First Direct doing that has converted so many of their customers into walking advertisements?

With current industry focus on 'customer experience' and 'customer insight', it is strange that in the sector where customer data are richest, and where CRM visions have consequently 
been taken further, that both the experience and the insight are still far from achieving the returns we all believe are there. What is holding us back?

The promises dripping from the 'Relationship Marketing' chalice persuaded many senior managers to approve huge investments in technology and human resources, with high expectations of marketing advantage and attractive returns. Moving from a product- to a customer-centric business model, however, is proving to be very difficult, lengthy and expensive for many companies, frequently generating more issues than opportunities. The widespread 'stop/go' experience of changing or abandoning new systems, organisational structures and internal processes in the past few years is obviously extremely wasteful. This represents erosion in investor confidence, not just in major customer development projects, but it also risks undermining marketing as a businessleading function. Why have several organisations made U-turns in 'customer investment' recently? Did new management not understand the claimed long-term returns available, was there a major performance gap versus expectations, or was the strategy sacrificed to a shorter-term cost purge? Irrespective, the promises were not believed. The problem is that the generic customer vision and performance expectations were correct, but the execution has often been lacking or flawed.

A major underlying hurdle is that technology is repeatedly allowed to become the main event of the 'customer driven marketing' revolution, when customer behaviour and proven customer performance should always lead the way. By technology I include hardware, software, systems, data processing, data management, data solutions, data tools: all the technological 'means' that can be brought to bear that should empower marketers to achieve the business 'ends' of 'identifying and satisfying customer needs ... at a profit'.

Letting the 'ends' drive the 'means' sounds simple, but it is a loaded phrase that always merits more attention than the frequent lip-service it is given to support a business case. This means 'putting knowledge first', not technology, by simulating and testing what actually works with consumers, well before building inflexible infrastructures for 'customer contact' to live in, based on assumptions of what will work and how it should be done. The 'customer tested approach' for each separate company, performed in situ, invariably delivers actionable learning, quickly and cost-effectively, while providing real proof and credibility on which to base a subsequent tailored, realistic investment strategy.

Another hurdle that impedes real progress is illustrated by a simple, muchabused phrase: 'the right message, to the right person, at the right time'. This mantra of Targeting is easily and frequently chanted, but it is actually very difficult to accomplish relevantly, repeatedly and profitably. Knowingly and unknowingly, marketing crimes are being committed daily under the targeting umbrella, significantly eroding marketing performance available via the effective use of data, and thus eroding investor confidence. After so many years of technical improvement, growth in data availability, targeting possibilities, articles, training and conferences, why is it that so many well-proved direct marketing basics continue to be ignored by so many? The use of good knowledge-building planning, pragmatic test design, control/silent cells to measure real incremental gain, correct sampling and correctly executed selections are just some examples of what I would describe as critical core marketing assets, without which massive, and often blind waste occurs. And we should beware: this basic matriculation is critical for the 
interactive future just ahead. 'What should be said to Whom, and When' in 'live' contact environments will have to be driven by tested 'best practice rules' that can only come from testing and analysis, grounded in good commercial use of maths and psychology, not technology. While we must apply our know-how to the 'live' interactive world, the basics remain the same, and ignorance or avoidance of these basics in the future will risk significant resource waste and brand erosion.

Given our future interactive interface with consumers, I must mention here the slow take-up by most companies to make any, or effective use of so-called 'data triggers'. 'When is the right time' is well known as a key driver for relevance and hence consumer response and conversion. Years of analysis repeatedly demonstrate that recency of customer activity is a key driver of subsequent behaviour, and shout out that 'timing is key' and multiplies performance, and should therefore be harnessed and used. The power of 'following the customer's current need' is self-evident over the counter, over the telephone, or in any live sales situation. Yet this fundamental truth appears to be underrated by many in the land of database, where seemingly impassable systems change, or management approval processes, which frequently block worthwhile improvement. When the power of acting 'when the customer is ready to buy', as opposed to 'when marketing is ready to sell' is tested and revealed, this major performance area will start shifting from dream to mainstream.

Interestingly, none of the above is new: it is (or should be) base camp for all experienced direct marketers. These are the age-old principles of 'champion/ challenger', 'test and roll-out' and 'hot names', that have made complete business sense for decades in the measurable medium that is 'direct marketing' (DM). Why is it that the term 'Direct Marketing' has increasingly been used to describe a tactical activity, when it actually represents one of the most strategic 'route to market' business decisions that so many companies have faced? The core DM skills I describe have been known for years, but risk being forgotten in the rapid rise of the 'customer movement', the growth of which has inevitably resulted in a fragmentation of the traditional DM discipline into several separate, specialist areas.

This skill fragmentation has led to a major underlying problem: an observable erosion in core DM skills and knowledge, particularly in basic areas like planning, testing, analysis and contact strategy. This has led to many client and supplier personnel working to support elements of marketing and operational processes, with only a partial perspective of DM basics. Many operating in database marketing, data analysis, information, market research, or customer insight departments, have had little or no experience of line marketing, where the key focus is on financial outcomes, particularly important in the highly measurable world of direct marketing. The converse is also true: many acquiring responsibility for communications or customer management have often had little exposure to the DM basics nor the use of complex data, channels, or techniques. The overall impact of this dilution in basic direct marketing skills, is less rigour, less insight, less innovation and less exploitation of the huge opportunities actually available via direct channels. This is an important issue given the inevitable future explosion in companies' use of direct channels, let alone the accelerating need to use multichannel contact strategies intelligently, particularly relevant in the financial services sector.

I have focused above on some of the major hurdles we need to jump over in order to make far more than we do from 'customer information', especially given the future market place. I have left one of 
the most frustrating hurdles till last: the human interface. As channels increasingly fragment and messages multiply, and companies endeavour to lower operating costs, the pressure will increase for companies to keep shifting from human to non-human points of contact, especially to online contact. But critical 'moments of truth' for consumer trust and loyalty will increasingly be driven by the after-sales experience, especially for first-time purchasers, or for those with questions or problems. Over the telephone, over the counter, on the doorstep, are examples of highly geared contacts that can easily and quickly lead in a few seconds to long-term retention or attrition of customers: every human encounter represents a potentially dramatic 'attitude crossroads'. Human channels are the most expensive, however, and are guaranteed to increase in cost versus non-human direct channels. The ongoing need to reduce costs has led to moving call centre operations offshore, or to shifting localised sales and service activity from people and high street locations, to centralised online and/or remote contact: the jury is still out as to which strategies actually deliver the greatest returns over time.

Relevantly, one can frequently observe human and non-human contact channel silos, in terms of marketing planning, data, budgets, goals and organisation. A worrying consequence of this is that data are predominantly used to empower nonhuman activity, but far less so to empower the human interface, where the opportunity for improved cost- effectiveness is actually many times higher. How can we address this? Probably by overcoming gaps in knowledge, skills and attitudes, in contrast with providing contact staff with 'data', 'prompts' and 'customer technology'. Where would you spend an incremental pound? On training contact staff to ask relevant questions, or on providing them with better information about the customer with whom they are interacting? My point is that we should do both.

Will the next 10-15 years of marketing be different from the last 10-15 years? Or will the longstanding lack of interest, apathy and inertia of so many financial services customers continue unabated, remaining a major driver of customer retention, despite dissatisfying customer experiences and competitive recruitment efforts? With the imminent onslaught of messages, in all places, at all times, 'moments of truth' will occur increasingly for all customers, and the immediate relevance and service they experience will increasingly determine long-term loyalty and advocacy.

Behind the scenes, how data are harnessed and used will determine the difference between success and failure. While we have to exploit all relevant technology and information opportunities, I believe that not confronting the underlying hurdles I have described above will compromise, if not eliminate our chances for success. 